\title{
Variances and correlations of milk production, fertility, longevity, and type traits over time in Australian Holstein cattle
}

\author{
M. Haile-Mariam ${ }^{*} \dagger^{1}$ and J. E. Pryce ${ }^{*} \dagger$ \\ *Department of Economic Development, Jobs, Transport and Resources, and \\ †Dairy Futures Cooperative Research Centre, La Trobe University, Bundoora VIC 3083, Australia
}

\begin{abstract}
When using historical data, it is often assumed that the genetic correlation of the same trait recorded at different time points is reasonably close to 1 . However, selection and possible changes in trait definitions means that this may not necessarily be the case. Regularly monitoring genetic parameters over time is important, as changes could reduce the accuracy of genetic evaluations. About 20 yr (1993 to 2012) of data on milk yield as well as functional and type traits from Australian Holstein dairy cattle were analyzed to assess changes in genetic correlations within and among traits over time by considering 2 traits at a time using linear random regression (RR) and multitrait (MT) models. Both residual and genetic variances for milk yield traits and calving interval (CI) increased over time, with the highest increase observed for protein yield. For most type traits some fluctuations over time were noted in both the residual and additive genetic variances. Genetic correlations among survival (i.e., from first to second lactation), milk yield traits, CI, and some type traits varied over time. The genetic correlation of the same trait (e.g., protein yield, fat yield, and some type traits) measured in different years was also less than $1.0(0.1-0.9)$, which is likely to be due to selection or changes in trait definitions. Estimates of parameters from the RR model were generally similar to those from MT models that considered the same trait recorded in different year groups as different traits. However, in the case of survival and CI (i.e., lowly heritable traits), the genetic correlations over time obtained from the MT model were lower $(0.21$ to 0.75$)$ than those from the RR models (0.9-1.0). Genetic correlations of survival with milk, fat, and protein yields declined from $\sim 0.4$ to 0.5 at the beginning of the study period $(1993 / 94)$ to zero or negative at the end $(2009 / 10)$, whereas the correlation between CI and milk yield became more
\end{abstract}

Received March 5, 2015.

Accepted June 11, 2015

${ }^{1}$ Corresponding author: Mekonnen.HaileMariam@ecodev.vic.gov.au unfavorable and increased from 0.3 to 0.5 over the same time period. The same pattern was observed for the genetic correlation between survival and CI, which also became more unfavorable over time and increased from 0.67 to 0.87 in absolute value. The genetic correlations of survival with type traits, such as angularity and body depth, decreased from near zero to negative $(-0.3$ to -0.4$)$. But genetic correlations between pin set and survival showed less variation $(0.2-0.3)$ over time. Similarly the genetic correlation of CI with body depth and angularity became more antagonistic over time. Over time the importance of traits such as milk yield and overall type as criteria for culling decreased, whereas the importance of fertility and possible disease incidence increased, implying that there has been a switch from voluntary to involuntary reasons dominating culling decisions. Changes in genetic correlations of the same trait and among traits over time have important implications on the accuracy of prediction of traits, such as survival and CI, which often rely on other traits as predictors and ultimately on the accuracy of genetic evaluations (traditional and genomic), and also the prediction of response to selection.

Key words: genetic correlation, random regression, genetic evaluation, type traits, functional traits

\section{INTRODUCTION}

In animal breeding, data collected over many years is often used for both genetic evaluation (traditional and genomic) and genome-wide association studies (GWAS). The main reason for using older data in genetic evaluations is to increase the amount of data used and ultimately the accuracy of EBV, and most models account for selection bias in this process. When using older or historical data, the basic assumption is that the genetic correlation of the same trait recorded at different time points is reasonably close to 1 and also variance component estimates are assumed to be constant over time. However, several factors, including selection, linkage disequilibrium, change in trait definition, and so on, could contribute to changes in variance of traits and correlations between traits. 
The correlation between the same trait over time can change either dramatically or gradually. For example, changes in correlations of survival with itself over time could happen gradually because of changes in culling reasons over time (Tsuruta et al., 2004a). However, change in definition of subjectively scored traits in particular, such as type and workability traits, can be more dramatic and may result in low correlations between data collected over time. This means that when functional traits are predicted from type and workability traits, the prediction equations need to be updated more frequently (Tsuruta et al., 2004a). Traits that have precise measurements, such as milk yield traits are less likely to change over time, but selection pressure on these traits could be high and this may cause changes in genetic variance and correlation among milk yield traits or their correlation with other traits (Tsuruta et al., 2004a). For example, genetic correlations among milk yield traits appear to have changed over the last $20 \mathrm{yr}$, presumably because of the strong of selection for protein yield (Bowman et al., 1996). Estimates based on data of Australian Holstein-Friesian cows collected before 1992 showed a genetic correlation between fat and milk yield of 0.78 (Visscher and Goddard, 1995), whereas the estimates based on more recent data are close to 0.3 [Kon Konstantinov, Australian Dairy Herd Improvement Scheme (ADHIS) Melbourne, Australia, personal communication]. Similar decreases in genetic correlations between milk and fat yield over time were also observed in the US Holstein data (Tsuruta et al., 2004a).

Knowing the extent of changes over time in genetic variances and covariances among traits could be useful to improve the effectiveness of selection schemes and accuracy of genetic or genomic evaluations. For example, if correlations between a trait measured at different time points are low, then genetic evaluations that consider the same trait recorded in different time periods as 2 different correlated traits may be better than models that ignore this information (Jamrozik and Schaeffer, 1991; De Jong and Harbers, 2002). If the changes that are observed in these traits are gradual, fitting an additive genetic effect with random regression (RR) on year of birth or calving to account for variation over time may be better (e.g., Tsuruta et al., 2004b). In fact, knowing the change in genetic covariances over time is very important, as large data sets that include a lot of historical data have been assembled for genomic prediction and GWAS. Knowing how covariances change over time can improve the subdivision of animals into training and validation groups for genomic prediction and GWAS as well as for improving prediction equations for economically important lowly heritable traits where either the predicted trait or its predictors change over time.
The current study examined estimates of variances and covariances among traits over time using data on milk yield, 2 functional traits (survival and fertility), and some type traits from Australian Holstein cows collected over the last $20 \mathrm{yr}$. The type traits considered were those correlated with milk yield or functional traits (Pryce et al., 2009; Haile-Mariam et al., 2014). These were 4 linear traits (body depth, angularity, udder depth, and pin set) and 2 composite traits (mammary system and overall type). The 2 composite traits were selected because 2 analyses (Battagin et al., 2012, 2013) that used data from about 20 Interbull-member countries showed that the cluster to which Australian data belonged changed more frequently over the study period (2001-2010), which could be indicative of change in definition of the traits. Furthermore, genomic analyses of Australian data (Haile-Mariam et al., 2015) showed that the reliability of direct genomic value (DGV) for validation bulls was particularly lower for mammary system and overall type compared with other traits with similar heritability $\left(h^{2}\right)$. In addition, the definitions of some traits changed in 2007 as part of the breed development program of Holstein Australia. Assessing the extent of the changes in the definitions of the traits and their correlation with other traits can give better insight into changes over time. Therefore the approach that was taken in our study was to carry out a series of bivariate analyses so that changes in one trait can be compared with another trait.

\section{MATERIALS AND METHODS}

\section{Data}

Two main data sets of first-parity Holstein-Friesian cows were used to estimate genetic parameters, including the relationship among dairy traits over time. The traits analyzed were fertility [calving interval (CI)], milk yield (305-d milk, fat, and protein yield), survival from first to second lactation (coded as 1 or 0 ), and some type traits (overall type, mammary system, body depth, angularity, udder depth, and pin set).

All the data used for our study were extracted from the ADHIS database. A detailed description of the data used is given elsewhere (Haile-Mariam et al., 2014). Briefly, relatively large herds, with at least 1,000 calving records between January 1993 and December 2010, were selected. Only bulls that were part of AI programs and that had at least 5 daughters were included. Additionally, the study was restricted to first-parity cows that calved between 18 and 38 mo of age. Milk, fat, and protein yield below 2,000 L, $50 \mathrm{~kg}$, and $45 \mathrm{~kg}$ and above $15,000 \mathrm{~L}, 800 \mathrm{~kg}$, and $600 \mathrm{~kg}$, respectively, were 
Table 1. Mean and SD of the different traits analyzed for first-parity Holstein cows over time

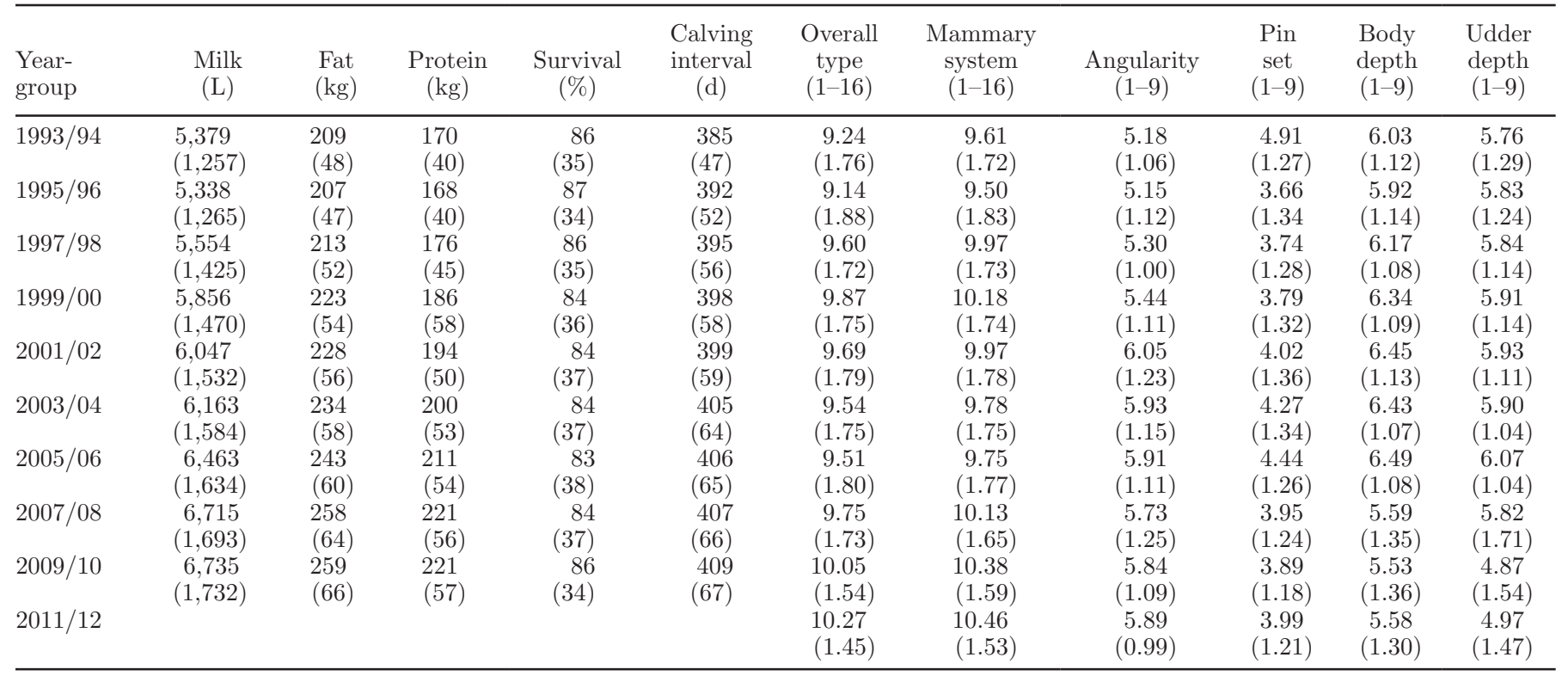

set to missing. To be valid, CI had to have a minimum length of $290 \mathrm{~d}$; CI between 550 and $762 \mathrm{~d}$ were set at a maximum of $551 \mathrm{~d}$ to minimize the influence of extremely long intervals on both the variance and mean. In addition, cows that were recorded as culled for fertility in the database were assigned a value for CI that is $3 \mathrm{~d}$ longer than the cow with the longest CI in the herd-year-season of calving (HYS; contemporary group). This edit resulted in including penalized CI records on about $14.2 \%$ of the cows that were coded 0 for survival (i.e., did not have CI).

The second data set used for our study included type scores carried out by HA classifiers once during the first lactation. Details of the type data used in the current study are described by Haile-Mariam et al. (2014). The type data used for this study included 436,896 cows that were classified between 1993 and 2012 that had linear type scores on a scale of 1 to 9 and composite type traits scored on the scale of 1 to 16 . Days in milk at classification were from 1 to 365 . Cows that calved for the first time after 38 mo of age and those classified after 49 mo of age were excluded. Type traits such as angularity, body depth, mammary system, overall type, pin set, and udder depth, which are associated with economically important traits (Pryce et al., 2009; HaileMariam et al., 2014) and those whose definitions were to some extent changed (Battagin et al., 2012, 2013), were considered for our study. A summary of the data on milk yield traits, CI, and survival and type traits, including the means and standard deviations over the year groups, is shown in Table 1. The data structure including number of cows with record, number of sires with progeny, and number of contemporary groups for year groups is given in Table 2 .

About $55 \%$ of cows with type data were identified as having records for other traits (milk yield, CI, and survival). These data were merged to explore possible changes in association between selected type and performance traits over time. To ensure that the exclusion of data of cows not type classified had a minimal effect on the genetic correlations between type traits and other traits, data of other cows were added if they were the progeny of sires with type data and if they were in the same contemporary group as type scored cows with their type data coded missing.

\section{Statistical Analyses}

All data analyses were carried out using ASReml (Gilmour et al., 2009). The fixed effects fitted when analyzing CI, production, and survival were HYS, month of calving (as cross classified), and age at calving (as a covariate). Sire was fitted as a random effect and included the additive numerator relationship (A) matrix. The A matrix was constructed using all the available ancestors of sires. The available pedigree information on all animals (sires) was traced back to the 1950s. Animals with unknown parents were grouped based on their birth year, country of origin, and sex according to standard ADHIS genetic evaluation procedures (ADHIS, 2004).

Initially, data were analyzed fitting the interaction of sire with year (year of calving for performance traits and year of scoring for type traits) using RR to inves- 
tigate changes in variance and covariance over time of the traits. However, the results were more consistent when 2 consecutive year groups were fitted together in the RR model instead of individual years. Therefore, all subsequent analyses were performed by merging data of 2 consecutive years into one group. To obtain better starting values and to determine the appropriate order of Legendre polynomials for modeling performance over time univariate analyses of all traits were carried out. For most traits the intercept and slope (i.e., linear regression) were found to be most appropriate based on log-likelihood ratio tests. Whereas, for some traits, such as survival, we found that only fitting the intercept was adequate. However, as the main interest of our study was to look at the association between traits over time, all results reported are from bivariate analyses fitting intercept and linear terms. Thus, data on all traits were analyzed by fitting a bivariate RR model, which allowed the variance and covariance estimates to vary over time.

$$
\begin{aligned}
Y_{t j k l m} & =\mu_{t}+\mathrm{HYS}_{t j}+M_{t k}+\sum_{n=1}^{2} B_{t n} \mathrm{Age}_{m n}+\sum_{n=0}^{1} Y_{t n} Y_{m n} \\
& +\sum_{n=0}^{1} S_{t l n} Y_{m n}+e_{t j k l m},
\end{aligned}
$$

where $Y_{t j k l m}$ is an observation on the th trait; $\mu_{t}$ is the overall mean of the th trait; $\mathrm{HYS}_{t j}$ is the effect of the $j$ th HYS on the th trait; $M_{t k}$ is the effect of the $k$ th month of calving on the th trait; $B_{t n}$ is a fixed regression coefficient of age at calving on the th trait; Age $_{m n}$ is the second order orthogonal polynomial corresponding to the $m$ th age of calving; $Y_{t n}$ is a fixed linear regression coefficient of year group on the th trait; $Y_{m n}$ is the $n$th order orthogonal polynomial corresponding to year groups on the $m$ th record; $S_{t l n}$ is an $\mathrm{RR}$ coefficient of the $\mathrm{th}$ sire additive effect and the $n \mathrm{th}$ year group on the th trait; $e_{t j k l m}$ is a random residual effect. When analyzing type data, herd-classifier-round and age at classification instead of HYS and age at calving, respectively, were fitted. In addition, DIM at classification was fitted as an additional covariate (Haile-Mariam et al., 2014). The variance-covariance structure (V) for the random effects, where $\mathbf{s}$ is vector of sire estimated breeding values and $\mathbf{e}$ is the vector residuals, is defined as:

$$
\mathrm{V}=\left[\begin{array}{l}
\mathbf{s} \\
\mathbf{e}
\end{array}\right]=\left[\begin{array}{cc}
\mathbf{G} \otimes A_{s} & 0 \\
0 & \mathbf{R} \otimes \mathbf{I}_{\mathbf{e}}
\end{array}\right],
$$

where $\mathbf{G}=$ sire variance-covariance matrix of size 4 $[2$ traits $\times$ (intercept + linear $)] ; A_{s}=$ additive genetic relationship among sires; $\mathbf{R}=$ heterogeneous residual variance-covariance matrix of $2 \times 2$ block diagonal matrices, one for each year group of size 8 to 10 (depending on the set of traits analyzed); $\mathbf{I}$ is identity matrix; and $\otimes$ is Kronecker product. In $\mathbf{R}$, covariances between traits are nonzero within year groups only. For the RR component, a Legendre polynomial fit of first (i.e., intercept and linear) order were fitted for all traits.

\section{Calculation of Genetic Parameters}

The additive sire covariances for year groups are calculated as $\Phi \operatorname{Var}(\mathbf{G}) \Phi^{\prime}$, where $\Phi$ is a matrix of Legendre polynomial coefficients value for each year groups of row (8-10) and the intercept and linear terms of columns (2). Matrix $\mathbf{G}$ is partitioned into 3 submatrices of size $2 \times 2$ and is premultiplied and postmultiplied

Table 2. Structure of the data [number of cows, sires, and herd-classifier-round (hrc) or herd-year-seasons (hys)] used for the different traits over time

\begin{tabular}{lccccccc}
\hline & \multicolumn{3}{c}{ With type data } & & \multicolumn{3}{c}{ With milk yield data } \\
\cline { 2 - 3 } \cline { 6 - 7 } $\begin{array}{l}\text { Year- } \\
\text { group }\end{array}$ & Cows & Sires & hrc & & Cows & Sires & hys \\
\hline $1993 / 94$ & 39,547 & 2,221 & 3,777 & & $45,886(0.30)^{1}$ & $1,041(0.94)^{2}$ & 3,092 \\
$1995 / 96$ & 51,396 & 2,391 & 3,547 & & $73,866(0.20)$ & $1,401(0.82)$ & 4,325 \\
$1997 / 98$ & 72,251 & 2,748 & 4,344 & & $102,116(0.44)$ & $1,963(0.95)$ & 5,921 \\
$1999 / 00$ & 77,668 & 2,774 & 4,134 & & $104,196(0.40)$ & $1,995(0.95)$ & 6,016 \\
$2001 / 02$ & 52,249 & 1,777 & 3,795 & & $106,657(0.29)$ & $1,919(0.97)$ & 6,220 \\
$2003 / 04$ & 36,428 & 1,325 & 3,234 & & $87,177(0.24)$ & $1,450(0.91)$ & 5,447 \\
$2005 / 06$ & 29,436 & 1,116 & 2,893 & & $78,401(0.26)$ & $1,286(0.87)$ & 4,908 \\
$2007 / 08$ & 26,865 & 968 & 2,544 & & $72,706(0.29)$ & $1,226(0.98)$ & 4,413 \\
$2009 / 10$ & 30,165 & 1,228 & 2,951 & & $46,206(0.24)$ & $1,026(0.90)$ & 2,977 \\
$2011 / 12$ & 21,330 & 835 & 2,185 & & & & \\
\hline
\end{tabular}

${ }^{1}$ Proportion of cows with both milk and type data in parentheses.

${ }^{2}$ Proportion of sires with both milk and type data in parentheses. 
by $\Phi$ to get variance-covariance for each trait and for the covariance between the traits. Then, the calculated covariance components of the RR coefficients for sire additive genetic and the residual variance for each period were used to derive $\mathrm{h}^{2}$ estimates. The covariance components are used to calculated genetic correlations within a trait over time and between traits over time.

The tabulated $h^{2}$ and genetic correlations for a trait over time were from the analyses where the maximum amount of data for a particular trait was used. For example, the $\mathrm{h}^{2}$ and genetic correlations over time for type traits are based on analyses that involved type traits only where data of up to 436,896 cows were used.

We also performed a multitrait (MT) analysis, where different periods were treated as separate traits, to verify the results from the $R R$ models and gauge standard errors of estimates. We used 2 traits (e.g., milk and fat yield) and 3 time intervals (i.e., the first, the middle, and the last period) in these analyses. The fixed effects fitted in these analyses were the same as those used in the RR models, but the random effect component was replaced by the interaction of sire and period (1 to 3 ) and traits (1 to 2 ). Bivariate 3 -period model analyses were run that included milk yield, fat, survival, CI, and selected type traits. These produced a 6 by 6 sire variance-covariance matrices. The choice of type traits included in the analyses with functional traits (survival or CI) were selected on the basis of results from preliminary analyses or previous studies (Pryce et al., 2009; Haile-Mariam et al., 2014). Also, the relationship between some type traits and overall type were estimated.

\section{RESULTS}

\section{Mean Performance}

The mean and standard deviation for milk yield traits and CI increased with time (Table 1). The trend in survival appears to be static over time. Among type traits, the mean overall type score of cows increased over time, whereas no clear trend was noted for other traits (Table 1). Over time, the amount of data used for our study varied (Table 2), largely due to the variation in the number of type scored cows. At the beginning of the study the number of cows that had valid CI and survival data were to some extent limited because of the decision to use cows that calved for the first time in 1993/94. Also, toward the end of the study period, the number of cows were reduced (Table 2 ) because only cows given adequate opportunity to recalve were considered. However, no deliberate selection occurred that might affect estimated genetic parameters over time.

\section{Variances Components and Heritabilities}

Figure 1 shows the residual and additive genetic variances for milk yield traits. Relative to the first period (1993/94), the additive genetic variance for protein, fat, and milk yield in the last period $(2009 / 10)$ increased by 17,11 , and $7 \%$, respectively. During the same period, the residual variance for protein, fat, and milk yield increased by 124,102 , and $92 \%$, respectively.

The additive genetic variance for CI varied from 131 to $121 \mathrm{~d}$ and the additive genetic variance for survival decreased from 52 to $31 \%$ when year-group of calving increased from 1993/94 to 2009/10. However, whereas the residual variance for CI more than doubled during the same period (Figure 2), the residual variance of survival did not change. The increases in variance from RR model observed were similar to those increases from MT models where data in different year-groups are considered as different traits (results not shown).

Table 3 shows that the $\mathrm{h}^{2}$ estimates from the $\mathrm{RR}$ model of both milk yield and functional traits were highest at the beginning of the study period (1993/94) and lowest toward the end of the study period (2008/09). These estimates are close to estimates from MT (Table 4).

The residual and additive genetic variances of udder depth and body depth increased in 2007/08 (Figure 3), possibly confirming that the definition of these traits changed at this time. For some traits, such as angularity, we observed a fluctuation in residual variation over the whole time period. Pin set was the only type trait where a reduction in residual variance was observed over time. The additive genetic variance of all traits, except udder depth and pin set, showed some curvilinear relationship with year group of classification.

The $\mathrm{h}^{2}$ of all type traits, except pin set and udder depth, decreased from their highest value in 1993/94 until they reached the lowest estimates, which were for cows classified in 2007/08 (Table 3). In the case of pin set, the lowest $h^{2}$ was in 2003/04, and for udder depth the highest $h^{2}$ was for cows classified during 2005/06 period. These estimates are comparable to estimates in Table 4 from MT models.

\section{Correlations Within Traits Across Time}

Figure 4 shows the genetic correlations of all other year groups with 1993/94 for milk yield traits, CI, and survival. The genetic correlations of the last year-group $(2009 / 10)$ with $1993 / 94$ is lowest for protein yield $(\sim 0.6$; Figure 4$)$ and the equivalent genetic correlation for survival was about 0.9 . These estimates are close to estimates from the MT models (Table 5). The excep- 


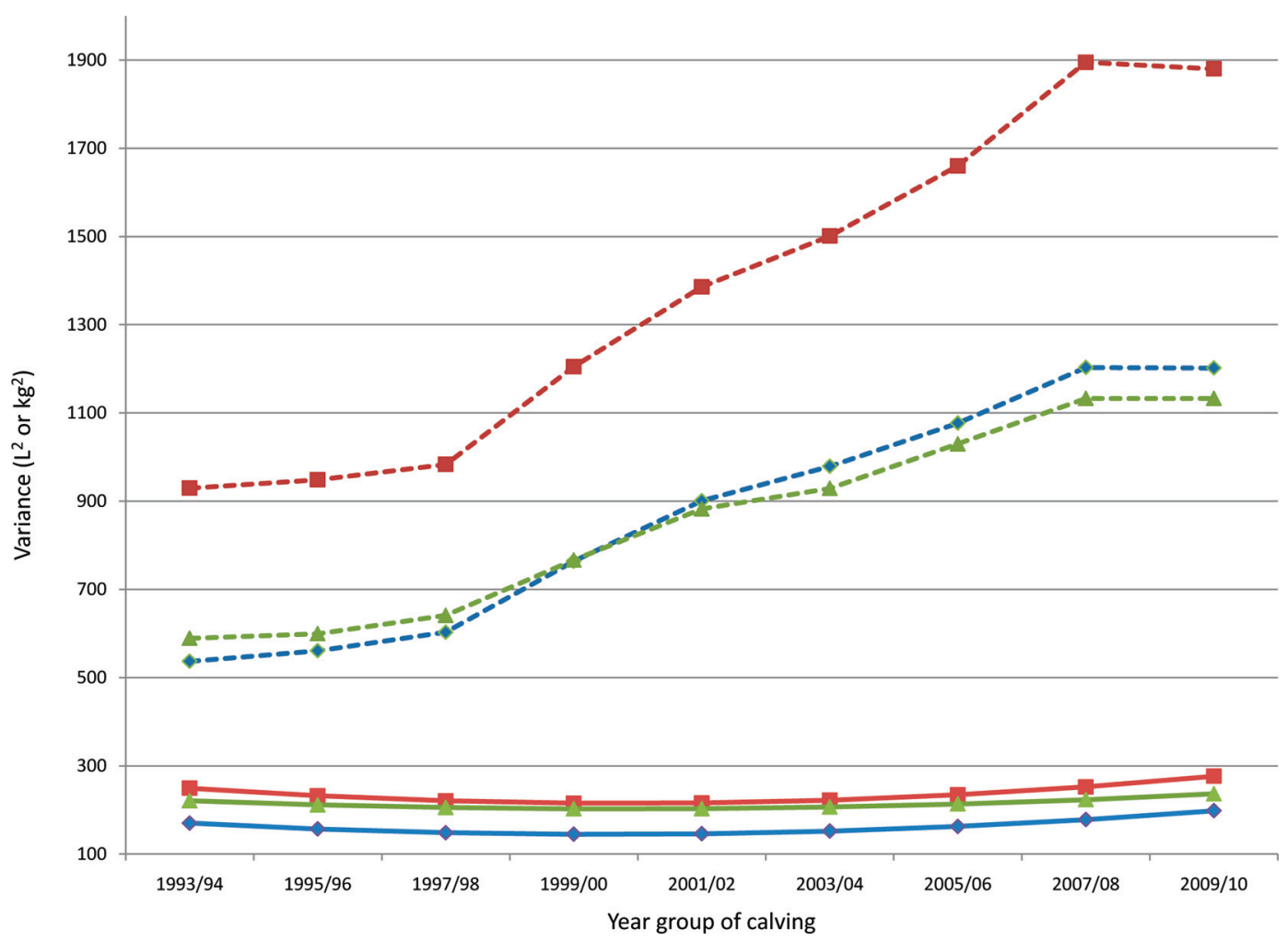

Figure 1. Residual variances (dashed lines) and additive genetic variances (solid lines) for milk $\times 10^{3}(\mathbf{\Lambda})$, fat $(\boldsymbol{\square})$, and protein $(\bullet)$ yield traits over time in first-parity Holstein cows. Color version available online.

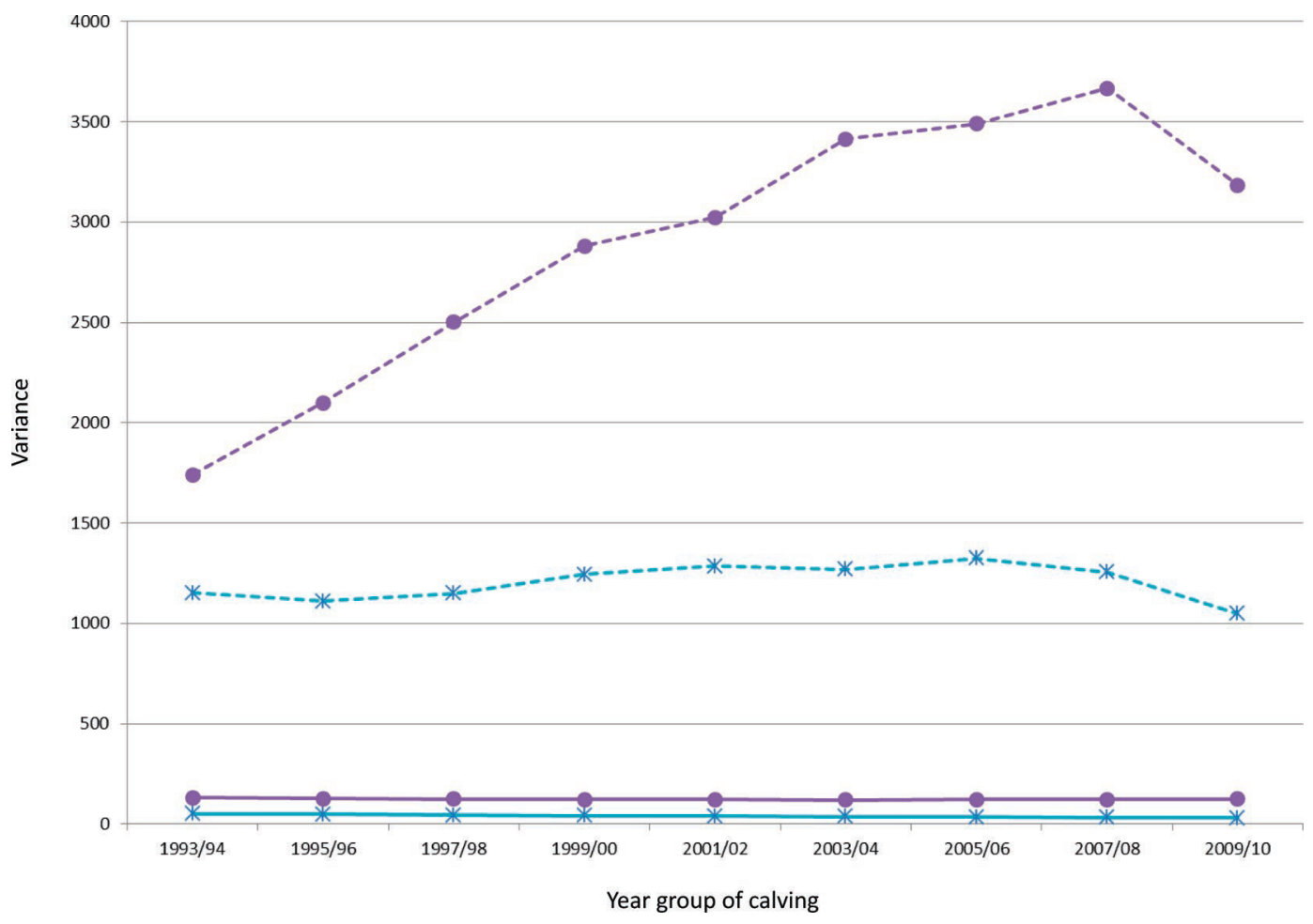

Figure 2. Residual (dashed lines) and genetic (solid lines) variances for calving interval $(\bullet)$ and survival $\left({ }^{*}\right)$ in first-parity Holstein cows. Color version available online. 
Table 3. Minimum and maximum $\mathrm{h}^{2}$ estimates and corresponding years for different traits over time from random regression models

\begin{tabular}{lcc}
\hline Trait & Minimum & Maximum \\
\hline Milk yield & $0.19(2007 / 08)$ & $0.34(1993 / 94)$ \\
Fat yield & $0.13(2007 / 08)$ & $0.25(1993 / 94)$ \\
Protein yield & $0.14(2007 / 08)$ & $0.30(1993 / 94)$ \\
Survival (\%) & $0.03(2007 / 08)$ & $0.07(1993 / 94)$ \\
Calving interval & $0.03(2007 / 08)$ & $0.06(1993 / 94)$ \\
Angularity & $0.15(2007 / 08)$ & $0.43(1993 / 94)$ \\
Pin set & $0.31(2003 / 04)$ & $0.54(1993 / 94)$ \\
Overall type & $0.13(2007 / 08)$ & $0.39(1993 / 94)$ \\
Mammary system & $0.14(2007 / 08)$ & $0.42(1993 / 94)$ \\
Body depth & $0.24(2007 / 08)$ & $0.44(1993 / 94)$ \\
Udder depth & $0.24(2007 / 08)$ & $0.44(2005 / 06)$ \\
\hline
\end{tabular}

tions are for CI and survival (i.e., low- $\mathrm{h}^{2}$ traits), where the estimates are also associated with large standard errors.

The genetic correlation of angularity measured in 2011/12 (the last period) was close to zero with angularity measured in 1993/94 (the first period), showing that the definition of this trait has changed considerably (Figure 5). Mammary system and overall type also changed considerably, with their genetic correlations between 1993/94 and 2011/12 being close to 0.3 (Figure $5)$. Table 5 shows that the change in definition of angularity probably happened earlier (2001/02), possibly with the intention to make its genetic correlation less antagonistic with fertility. Similarly the RR model also shows an earlier change in slope for angularity than for overall type or mammary system, which agrees with the trend observed in the MT models. The genetic correlation of pin set measured in 1993/94 and in 2011/12 was high, at 0.92 , which also agrees with the results from the MT models. Change in genetic correlation for body and udder depth (Figure 5) over time were more than that of pin set.

\section{Correlations Between Traits Across Time}

Both the genetic and residual correlation of protein yield with milk yield and the residual correlation of fat yield with milk yield remained constant over the years (Figure 6), whereas the genetic correlation of fat yield with milk yield decreased from 0.59 in 1993/94 to 0.35 in 2009/10. These results are consistent with those in Table 6, where the genetic correlations between milk and fat yield, for example, also decreased. The genetic correlation of 0.42 (Table 6 ) in the last year-group did not agree with the trend from the RR model. Further analyses showed that the genetic correlation $( \pm \mathrm{SE})$ between the first year-group (1993/94) and 2007/08 was $0.34 \pm 0.06$, which is in agreement with the result from the RR model.

The genetic correlation of milk yield with CI increased from 0.31 to 0.50 when the years of calving were 1993/94 and 2009/10, respectively (Figure 7). In contrast, the genetic correlation between milk yield and survival decreased from 0.45 in $1993 / 94$ to -0.15 in $2009 / 10$. At the same time, the genetic relationship of survival with protein yield also showed a similar change ( $\sim 0.47$ in $1993 / 94$ to -0.05 in $2009 / 10$ ). This agreed with the change in correlation between EBV for protein yield and survival for bulls (7,982 bulls) born before 2003 from 0.47 to 0.04 for bulls (633 bulls) born after 2005. The residual correlation of CI and survival with milk yield varied within a narrow range of 0.0 to 0.27 .

The change in definition of angularity over time is illustrated (Figure 8) more clearly by comparing it with body depth (a trait that changed less over time), where they are analyzed together. The correlation between body depth and angularity had a small negative correlation (both the residual and genetic correlation) at the beginning of the study (the first period), which changed into a high genetic correlation $(\sim 0.8)$ by the end of the study period (the last period).

Table 4. Heritability estimates with SE for selected traits at 3 time periods (1993/94, 2001/02, and 2009/10) where data in each time period were considered to be different traits

\begin{tabular}{lccc}
\hline & & Period \\
\cline { 2 - 4 } Trait & $1993 / 94$ & $2001 / 02$ & $2009 / 10$ \\
\hline Milk yield & $0.27 \pm 0.02$ & $0.21 \pm 0.01$ & $0.20 \pm 0.02$ \\
Fat yield & $0.17 \pm 0.02$ & $0.15 \pm 0.01$ & $0.14 \pm 0.02$ \\
Protein yield & $0.23 \pm 0.02$ & $0.16 \pm 0.01$ & $0.17 \pm 0.02$ \\
Survival & $0.04 \pm 0.01$ & $0.02 \pm 0.0$ & $0.03 \pm 0.01$ \\
Calving interval & $0.04 \pm 0.01$ & $0.04 \pm 0.01$ & $0.03 \pm 0.01$ \\
Angularity & $0.27 \pm 0.02$ & $0.14 \pm 0.01$ & $0.15 \pm 0.02$ \\
Pin set & $0.38 \pm 0.03$ & $0.29 \pm 0.02$ & $0.30 \pm 0.03$ \\
Overall type & $0.22 \pm 0.02$ & $0.21 \pm 0.02$ & $0.14 \pm 0.02$ \\
Mammary system & $0.25 \pm 0.02$ & $0.21 \pm 0.02$ & $0.15 \pm 0.02$ \\
Body depth & $0.30 \pm 0.03$ & $0.32 \pm 0.02$ & $0.21 \pm 0.02$ \\
Udder depth & $0.29 \pm 0.02$ & $0.39 \pm 0.03$ & $0.28 \pm 0.03$ \\
\hline
\end{tabular}




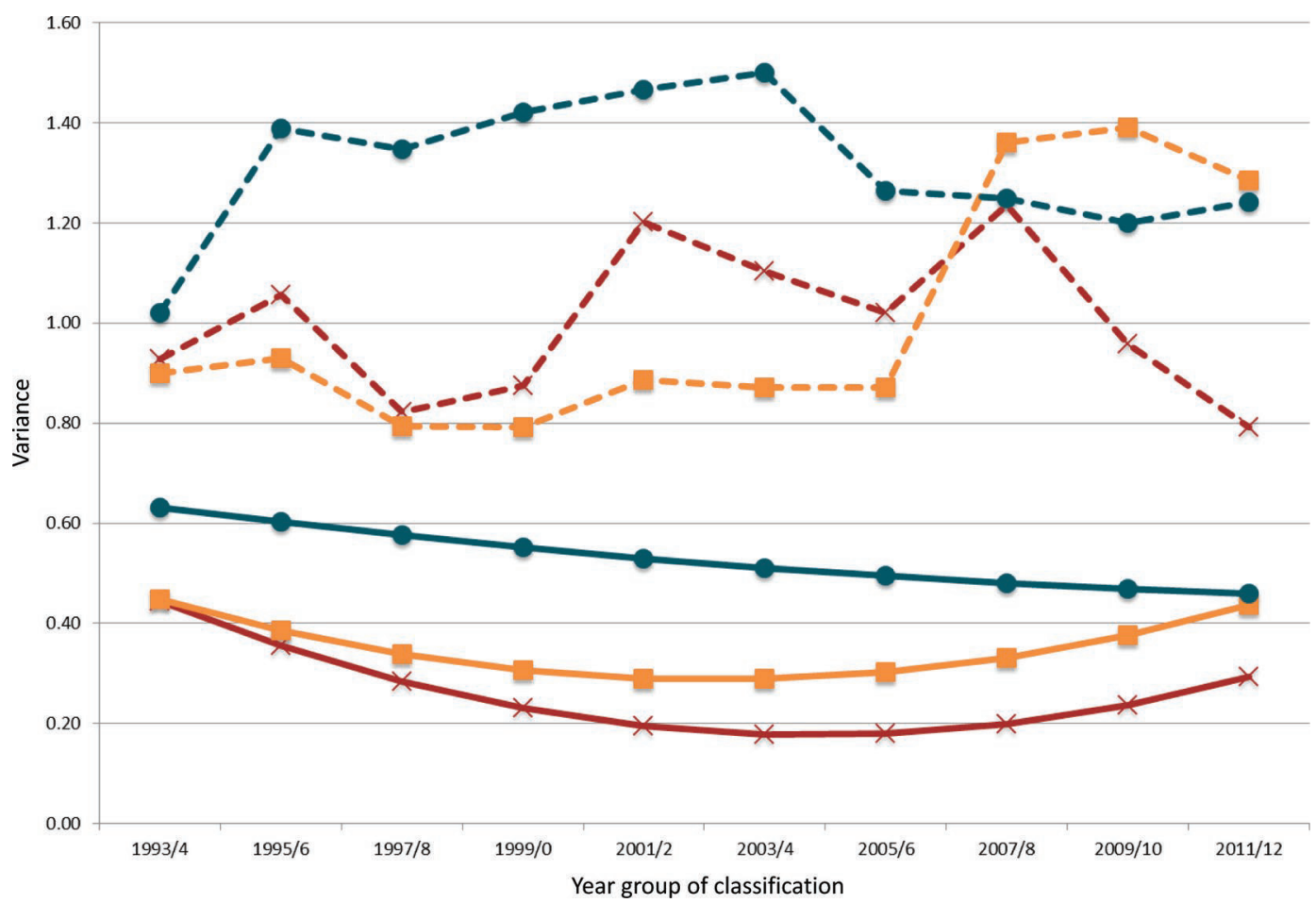

Figure 3. Residual (dashed lines) and genetic (solid lines) variances for cows assessed from 1993/94 to 2011/12 for angularity ( $\times$ ), body depth (ם), and pin set $(\bullet)$ in first-parity Holstein cows. Color version available online.

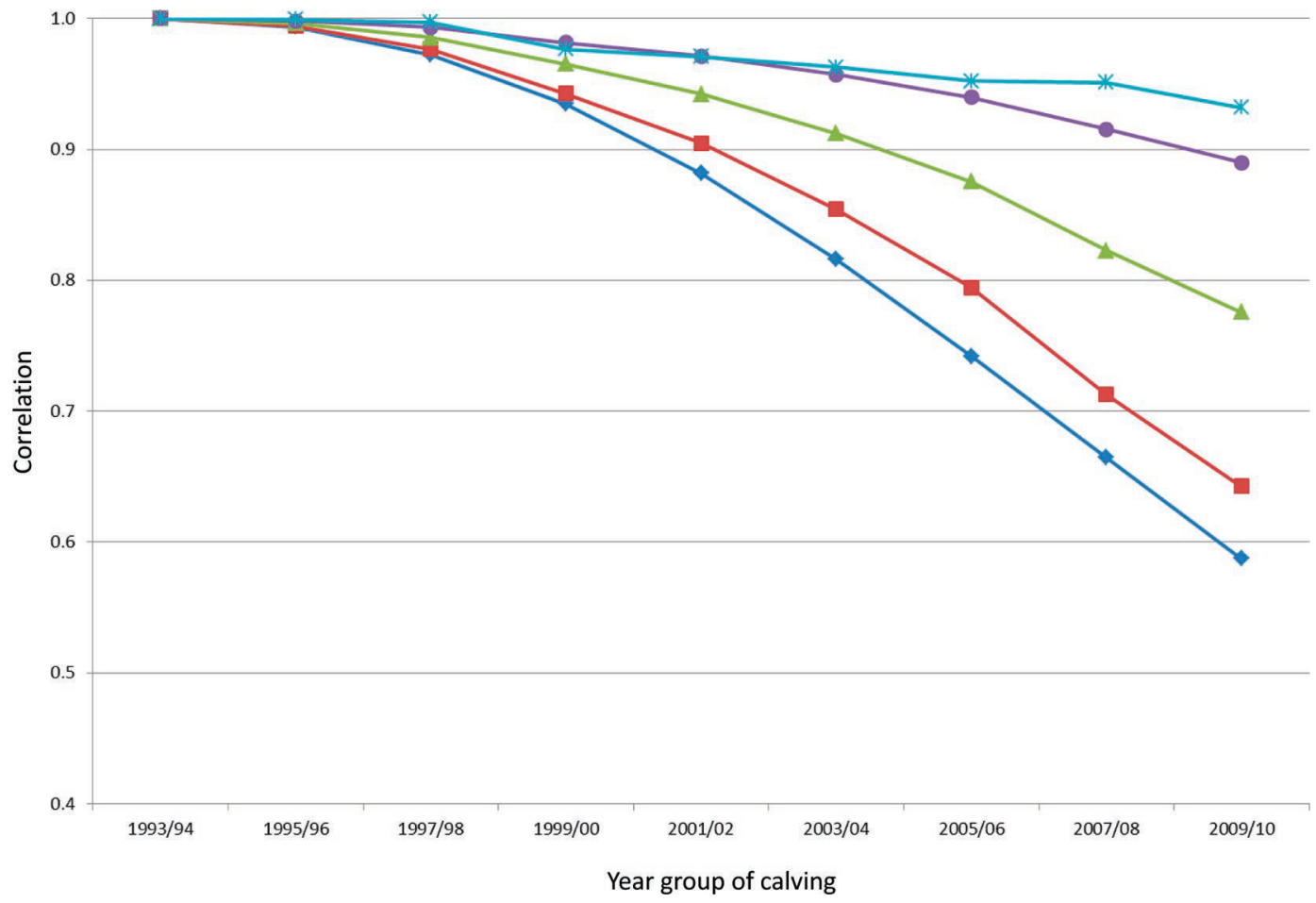

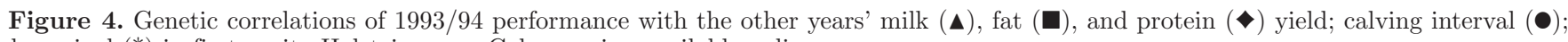
and survival $(*)$ in first-parity Holstein cows. Color version available online. 


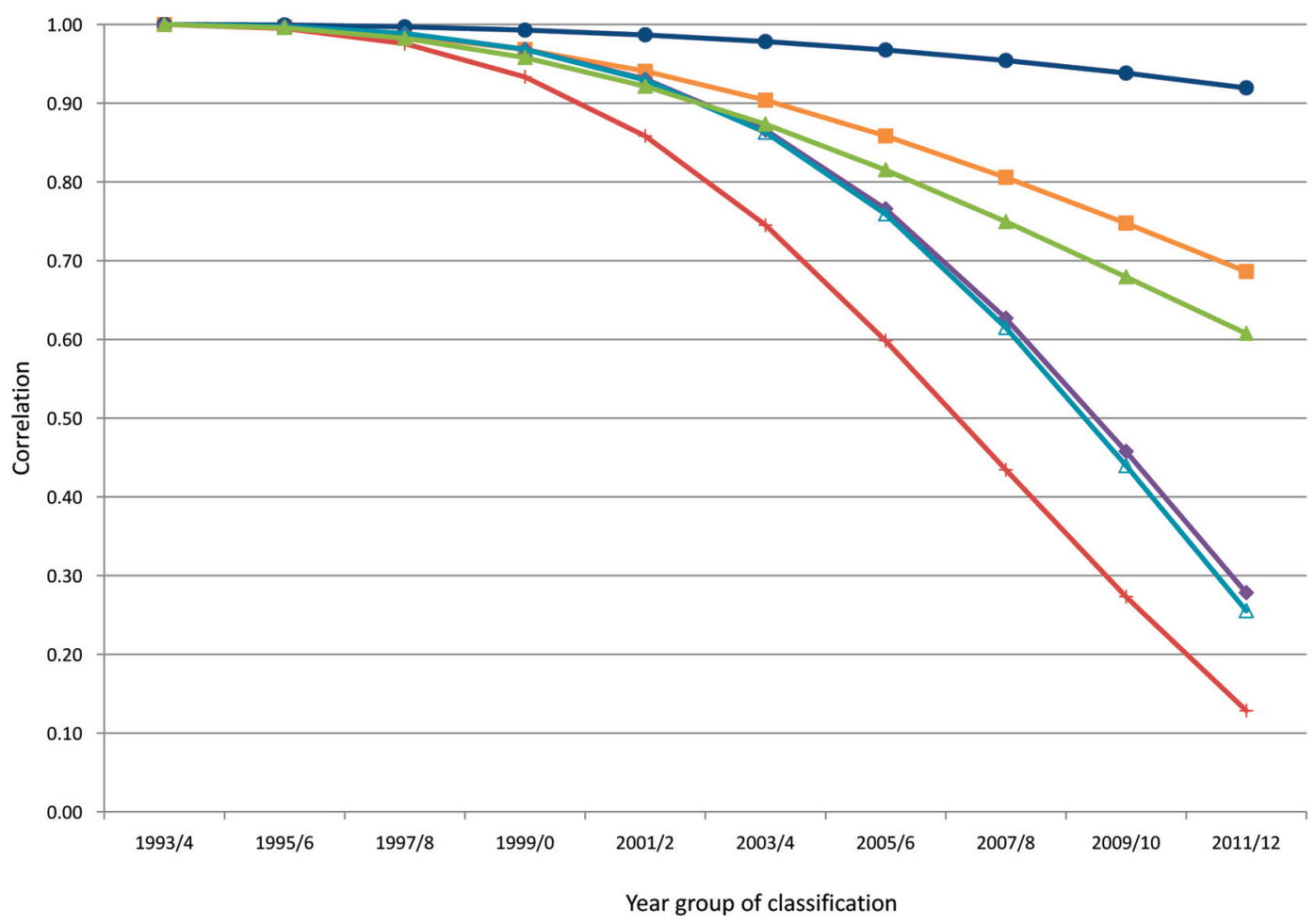

Figure 5. Genetic correlations of the same trait scored in 1993/94 and later years for angularity $(\times)$, body depth $(\boldsymbol{\square})$, pin set $(\bullet)$, udder depth $(\mathbf{\Lambda})$, mammary system $(\Delta)$, and overall type $(\checkmark)$ in first-parity Holstein cows. Color version available online.

The trend over time in the correlation of mammary system, angularity, and pin set with overall type is shown in Figure 9, where their correlations (both residual and genetic) increased, with the exception of mammary system. Both the residual and genetic correlations of mammary system with overall type remained high until it started to decline in cows classified in $2007 / 08$, possibly due to change in the definition of the traits. These results are in general agreement with those in Table 6 (i.e., MT model).
The correlations (i.e., genetic and residual) of milk yield with overall type, angularity, and body depth over time from the RR model are shown in Figure 10. The residual correlations of the 3 type traits with milk yield varied within a narrow range (0.05 to 0.18$)$ and are similar to those from the MT model (Table 6). The genetic correlation of milk yield with angularity showed a curvilinear relationship. In the case of overall type and body depth, the genetic correlation declined from 0.40 and 0.37 in cows that calved in the first period

Table 5. Genetic correlation estimates with SE for selected traits at 3 time periods $(1993 / 94,2001 / 02$, and 2009/10) where data in each time period were considered to be different traits

\begin{tabular}{lccc}
\hline & \multicolumn{3}{c}{ Period combination } \\
\cline { 2 - 4 } Trait & $1993 / 94$ and $2001 / 02$ & $1993 / 94$ and $2009 / 10$ & $2001 / 02$ and $2009 / 10$ \\
\hline Milk yield & $0.74 \pm 0.10$ & $0.72 \pm 0.20$ & $0.95 \pm 0.07$ \\
Fat yield & $0.69 \pm 0.12$ & $0.60 \pm 0.30$ & $0.83 \pm 0.11$ \\
Protein yield & $0.60 \pm 0.12$ & $0.62 \pm 0.23$ & $0.94 \pm 0.07$ \\
Survival & $0.68 \pm 0.29$ & $0.21 \pm 0.63$ & $0.35 \pm 0.32$ \\
Calving interval & $0.74 \pm 0.28$ & $0.75 \pm 0.66$ & $0.80 \pm 0.10$ \\
Angularity & $0.42 \pm 0.13$ & $0.35 \pm 0.36$ & $0.93 \pm 0.06$ \\
Pin set & $0.85 \pm 0.08$ & $0.75 \pm 0.21$ & $0.31 \pm 0.19$ \\
Overall type & $0.76 \pm 0.10$ & $0.18 \pm 0.29$ & $0.55 \pm 0.12$ \\
Mammary system & $0.77 \pm 0.10$ & $0.21 \pm 0.27$ & $0.86 \pm 0.10$ \\
Body depth & $0.86 \pm 0.07$ & $0.54 \pm 0.21$ & $0.70 \pm 0.11$ \\
Udder depth & $0.53 \pm 0.14$ & & \\
\hline
\end{tabular}


Table 6. Estimates of genetic and residual correlations within periods between traits over time from analyses that considered data in different periods as different traits for selected trait combinations

\begin{tabular}{|c|c|c|c|c|c|c|}
\hline \multirow{2}{*}{$\begin{array}{l}\text { Trait } \\
\text { combination }^{1}\end{array}$} & \multicolumn{2}{|c|}{ 1993/94 } & \multicolumn{2}{|c|}{$2001 / 02$} & \multicolumn{2}{|c|}{$2009 / 10$} \\
\hline & Genetic & Residual & Genetic & Residual & Genetic & Residual \\
\hline Fat, protein & $0.60 \pm 0.05$ & $0.82 \pm 0.0$ & $0.56 \pm 0.04$ & $0.83 \pm 0.0$ & $0.61 \pm 0.05$ & $0.82 \pm 0.0$ \\
\hline Milk, CINT & $0.21 \pm 0.11$ & $0.18 \pm 0.01$ & $0.37 \pm 0.08$ & $0.28 \pm 0.0$ & $0.37 \pm 0.12$ & $0.23 \pm 0.01$ \\
\hline Milk, surv & $0.33 \pm 0.11$ & $0.11 \pm 0.0$ & $0.08 \pm 0.11$ & $0.03 \pm 0.0$ & $-0.09 \pm 0.11$ & $0.14 \pm 0.01$ \\
\hline Fat, surv & $0.21 \pm 0.12$ & $0.10 \pm 0.0$ & $0.04 \pm 0.11$ & $0.02 \pm 0.0$ & $-0.14 \pm 0.15$ & $0.10 \pm 0.01$ \\
\hline OT, pin set & $-0.28 \pm 0.06$ & $-0.11 \pm 0.01$ & $0.07 \pm 0.06$ & $-0.02 \pm 0.0$ & $0.36 \pm 0.08$ & $0.13 \pm 0.01$ \\
\hline $\mathrm{BD}$, ang & $-0.21 \pm 0.06$ & $-0.27 \pm 0.01$ & $0.60 \pm 0.05$ & $0.37 \pm 0.0$ & $0.61 \pm 0.06$ & $0.45 \pm 0.0$ \\
\hline Milk, OT & $0.31 \pm 0.09$ & $0.18 \pm 0.01$ & $0.29 \pm 0.09$ & $0.13 \pm 0.01$ & $0.06 \pm 0.13$ & $0.10 \pm 0.01$ \\
\hline Milk, ang & $0.02 \pm 0.09$ & $0.06 \pm 0.01$ & $0.42 \pm 0.08$ & $0.13 \pm 0.01$ & $0.15 \pm 0.13$ & $0.16 \pm 0.01$ \\
\hline Milk, BD & $0.24 \pm 0.09$ & $0.13 \pm 0.01$ & $0.26 \pm 0.08$ & $0.11 \pm 0.01$ & $0.20 \pm 0.11$ & $0.09 \pm 0.01$ \\
\hline Surv, OT & $0.18 \pm 0.18$ & $0.09 \pm 0.01$ & $0.12 \pm 0.11$ & $0.10 \pm 0.01$ & $0.13 \pm 0.13$ & $0.10 \pm 0.01$ \\
\hline Surv, ang & $-0.20 \pm 0.18$ & $-0.02 \pm 0.01$ & $-0.18 \pm 0.12$ & $0.02 \pm 0.01$ & $-0.14 \pm 0.13$ & $0.02 \pm 0.01$ \\
\hline
\end{tabular}

${ }^{1} \mathrm{CINT}=$ calving interval; surv $=$ survival; OT $=$ overall type; ang = angularity; mam = mammary system; BD = body depth.

$(1993 / 94)$ to 0.29 and 0.23 in cows that calved at the last period (2009/10), respectively (Figure 10). The genetic correlation of body depth with milk yield over time from the MT model (Table 6) varied less than that from the RR model.
Figure 11 shows the genetic correlations from the RR model of survival (adjusted and unadjusted for milk yield) with angularity, udder depth, overall type, pin set, and body depth. Over time the correlation of survival with udder depth increased, whereas that with

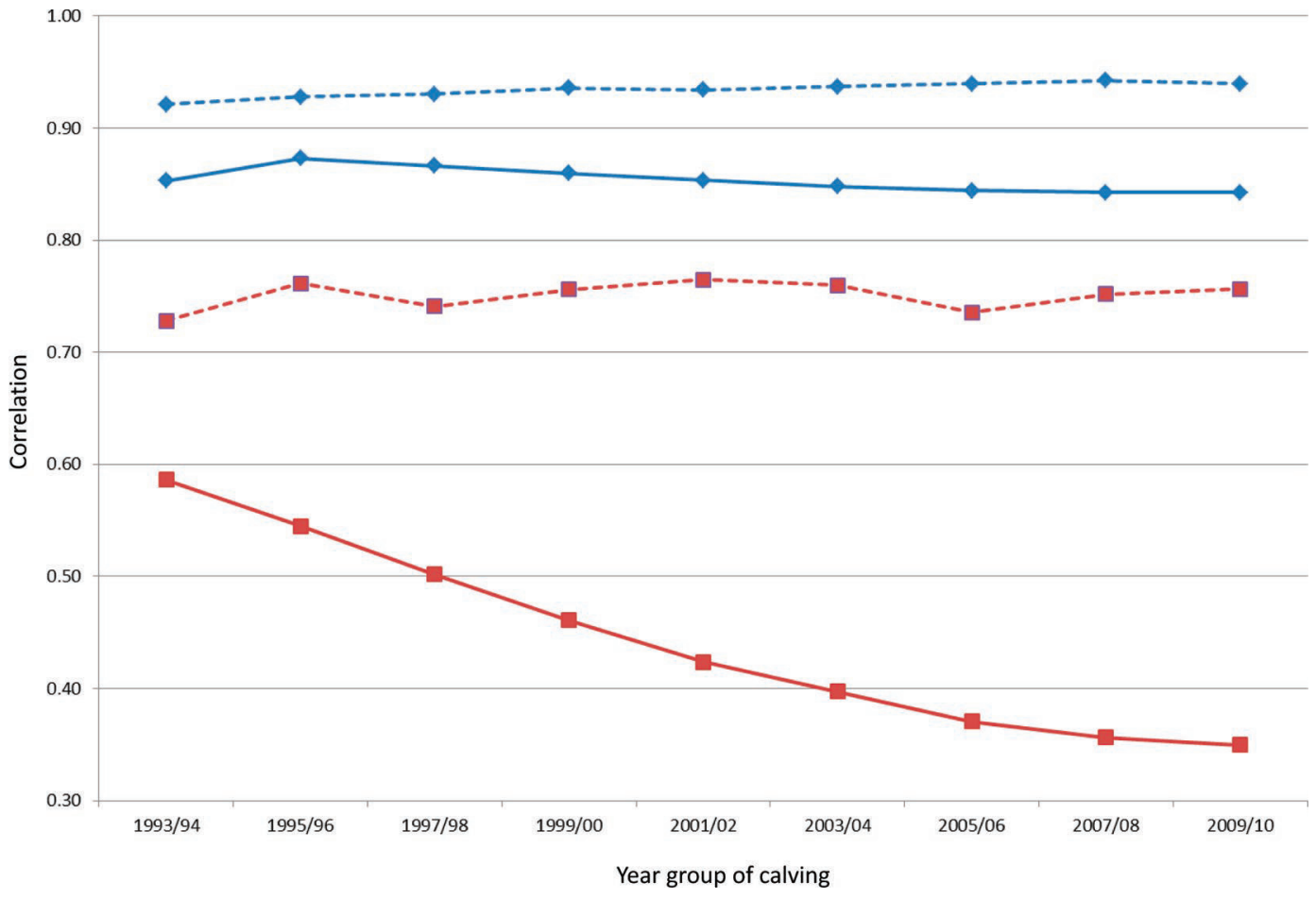

Figure 6. Genetic (solid line) and residual (dashed line) correlations of fat ( $\mathbf{\square})$ and protein ( ) yield traits with milk yield over time in firstparity Holstein cows. Color version available online. 


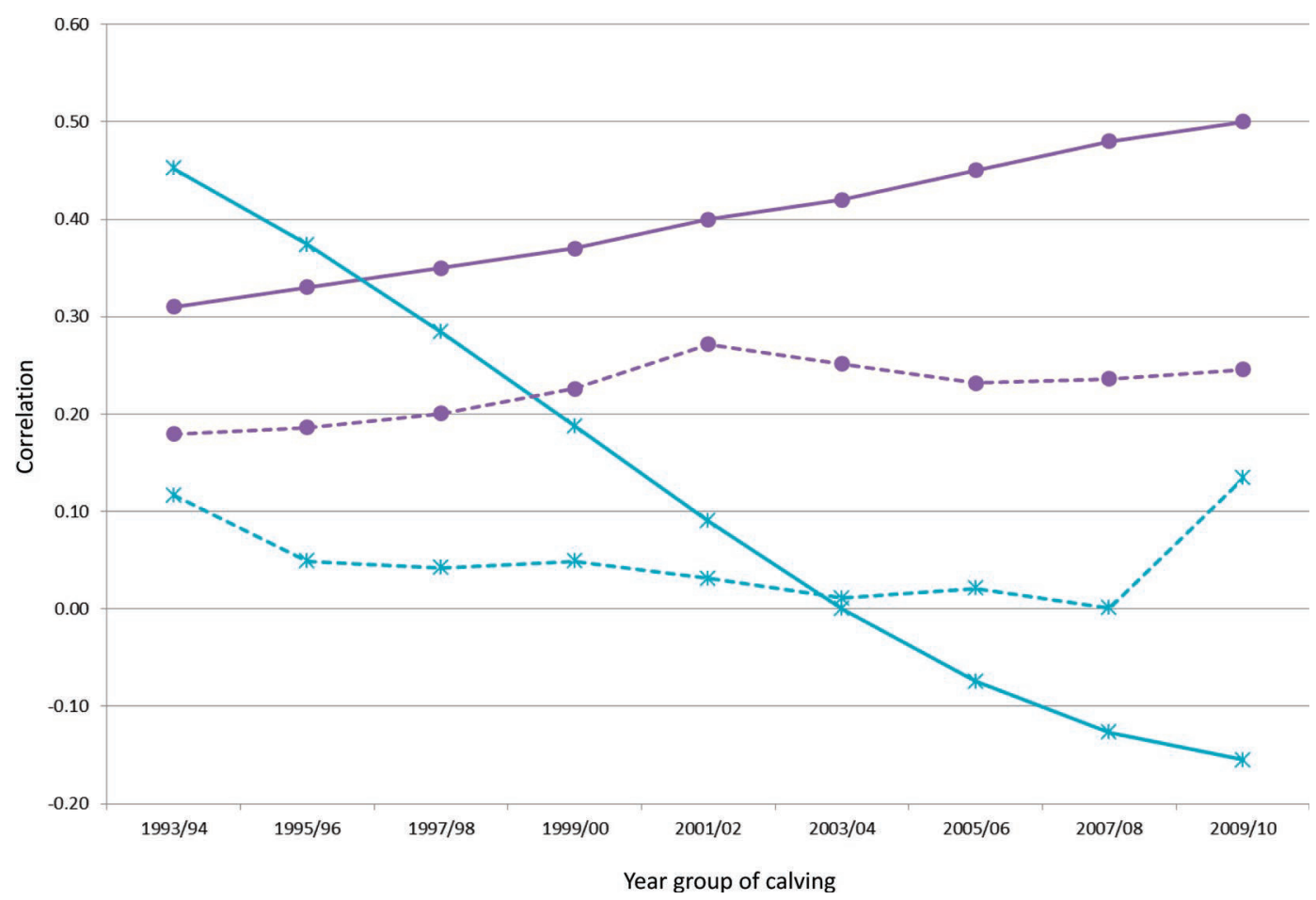

Figure 7. Genetic (solid lines) and residual (dashed lines) correlations of calving interval $(\bullet)$ and survival $(*)$ with milk yield over time in first-parity Holstein cows. Color version available online.

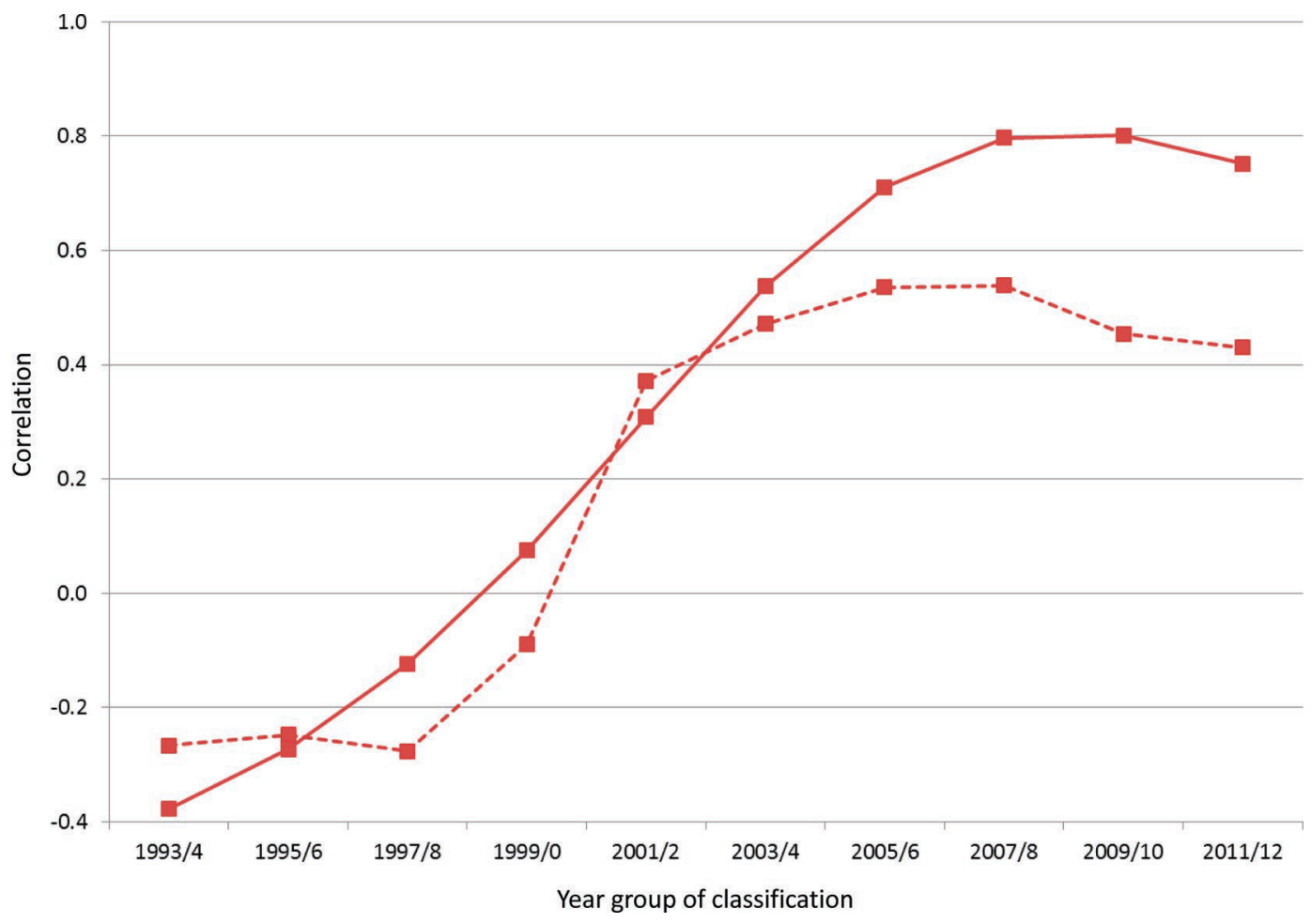

Figure 8. Genetic (solid lines) and residual (dashed lines) correlations from 1993/94 to 2011/12 between body depth and angularity in firstparity Holstein cows. Color version available online. 


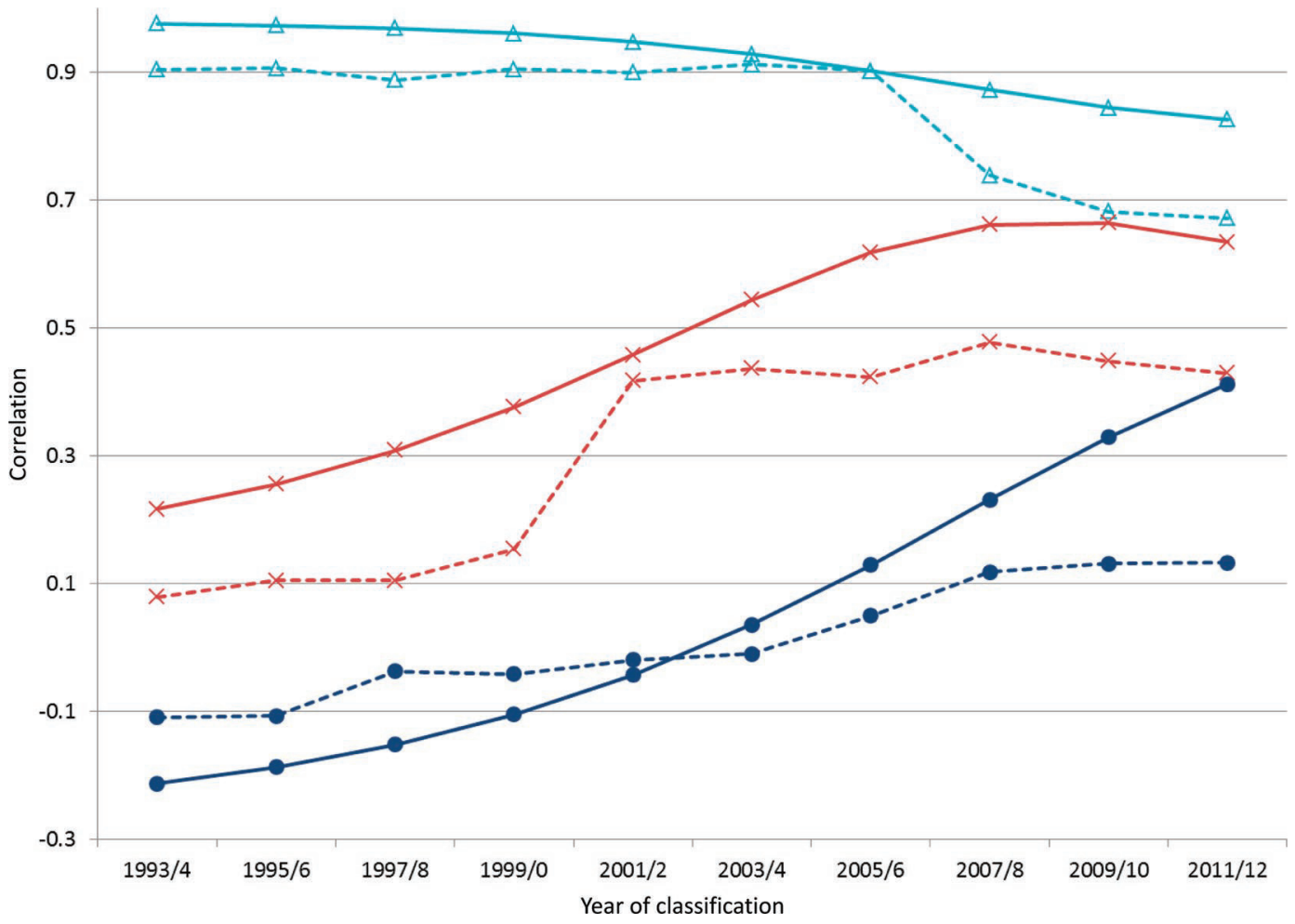

Figure 9. Residual (dashed lines) and genetic (solid lines) correlations scored in 1993/94 and later years of overall type with angularity $(\times)$, pin set $(\bullet)$, and mammary system $(\Delta)$ in first-parity Holstein cows. Color version available online.

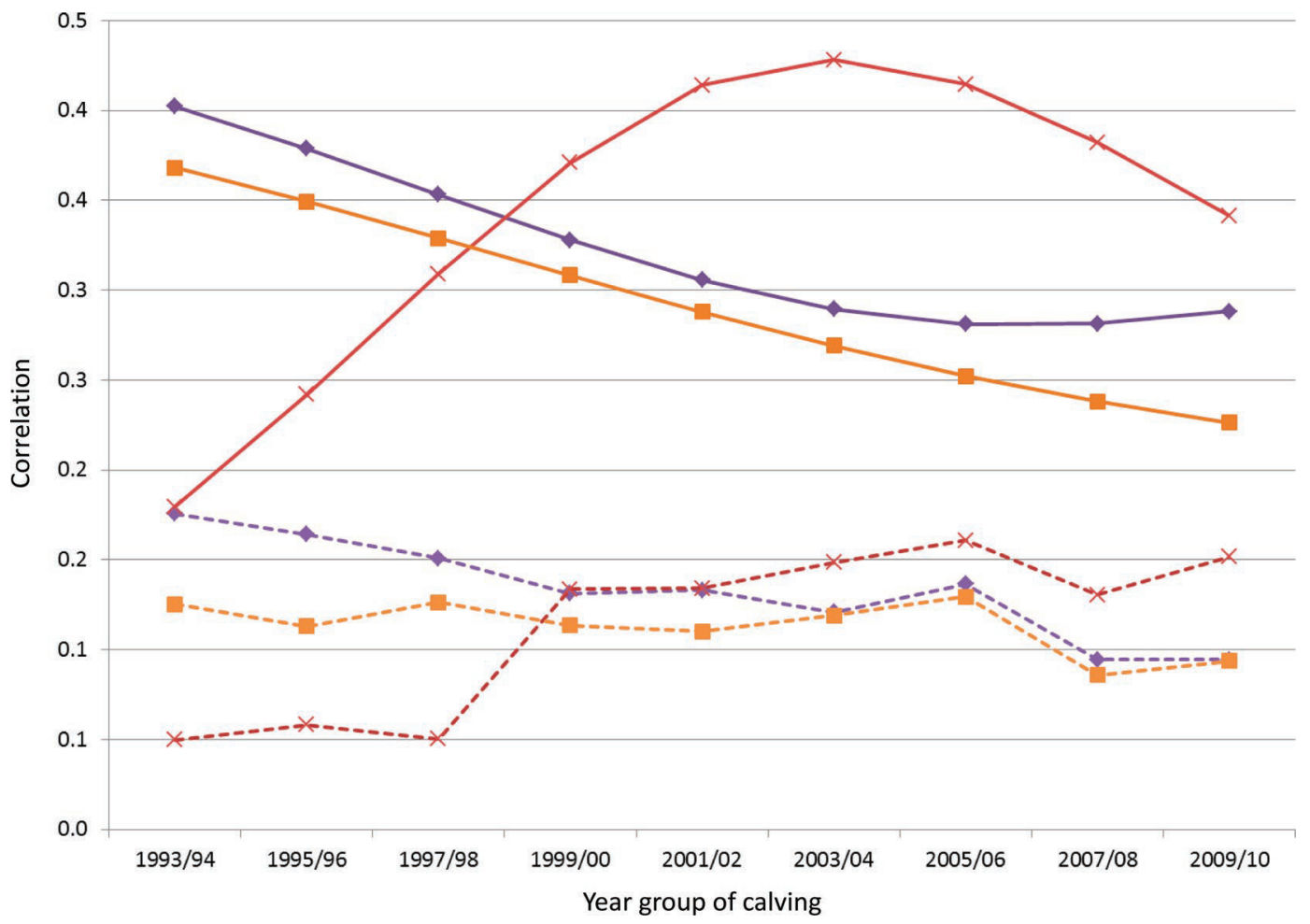

Figure 10. Residual (dashed lines) and genetic (solid lines) correlations scored in 1993/94 and later years of milk yield with angularity ( $\times$ ), body depth $(\mathbf{\square})$, and overall type $(\bullet)$ in first-parity Holstein cows. Color version available online. 


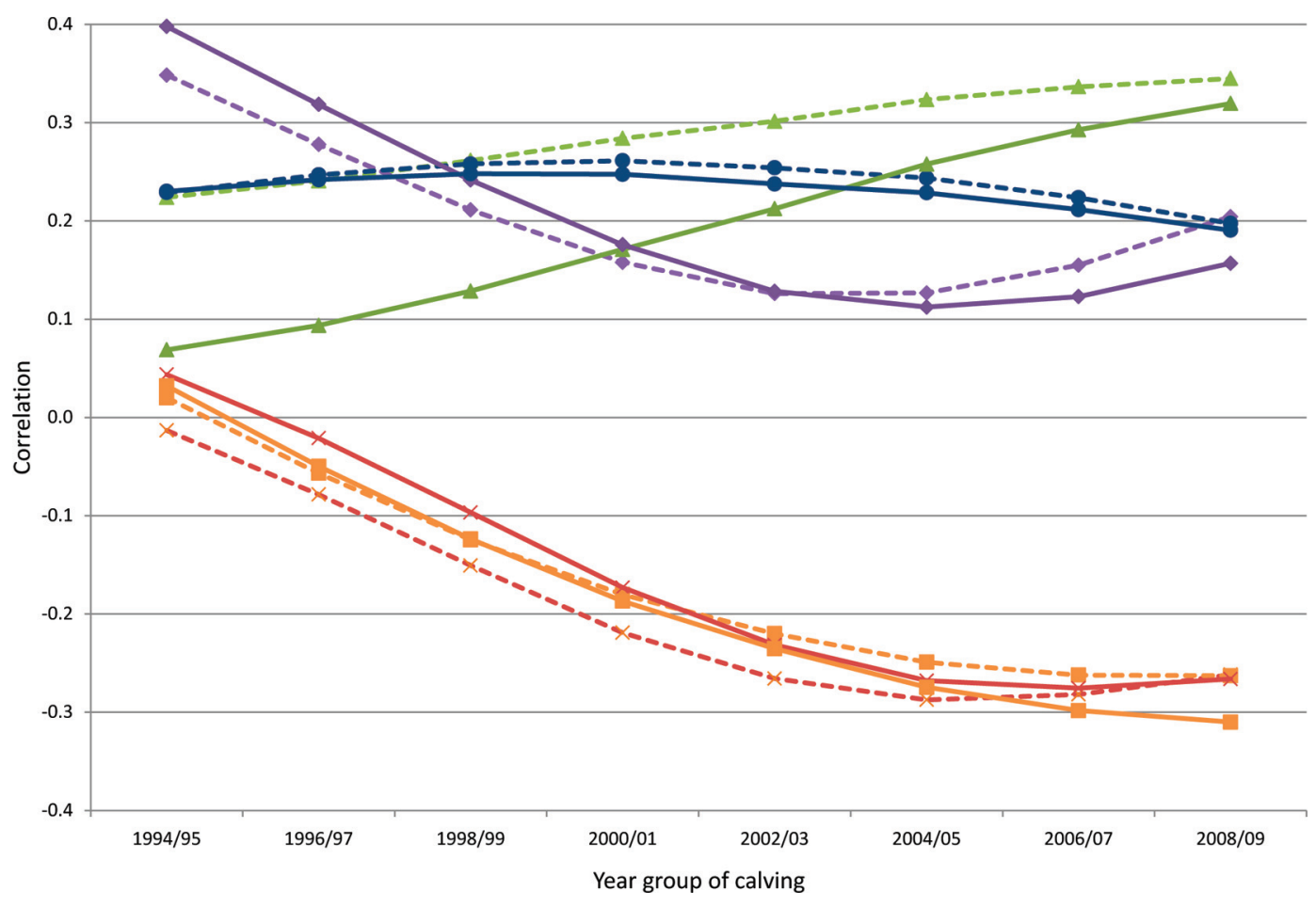

Figure 11. Genetic correlations of survival over time with angularity $(\times)$, body depth $(\mathbf{\square})$, pin set $(\bullet)$, udder depth $(\mathbf{\Lambda})$, and overall type $(\diamond)$. Solid and broken lines are survival unadjusted and adjusted for milk yield. Color version available online.

overall type, angularity, and body depth decreased. In contrast, the genetic correlation of survival with pin set did not change substantially over time. The corresponding results from the MT model are in Table 6 . The genetic correlation of CI with angularity, overall type, body depth, and udder depth (Figure 12) varied over time. Notably the correlation between angularity and CI varied between 0.13 and 0.57 . Table 6 shows the genetic and residual correlation of overall type, angularity, and body depth with CI from the MT model.

\section{DISCUSSION}

The main objective of our study was to assess the level of change in genetic correlations of a trait and among traits over time and examine the implications. In general, 3 categories of traits were identified. The first group includes traits, such as pin set, which showed no or little change over time. The second category of traits, such as milk yield traits (mainly protein and fat yield), are those which showed moderate change over time, which could have been due to selection. The additive genetic variance for these traits also showed change (e.g., protein yield). Mammary system, overall type, and angularity are the traits that showed the lowest correlation between the most distant time periods. This is likely to be because of changes in the definitions of these traits in addition to some level of selection.

Changes were observed in genetic correlations between milk yield traits and survival over time from the bivariate RR and the MT models, suggesting that factors that affect culling decisions have changed considerably over time. For example, in recent years the risk of culling of high-producing cows due to poor fertility has increased where the genetic correlation between CI and survival strengthen over time from -0.67 (beginning of the study) to -0.87 (at the end of the study), though the standard error of these estimates are likely to be high. In fact, our results from MT models imply that there has been a switch from voluntary to involuntary reasons dominating culling decisions. This has important implications because changes in genetic correlations of the same trait and among traits over time affect the accuracy of prediction of traits, such as survival and CI, which often rely on other traits (such as milk and type) as predictors (Boldman et al., 1992; Weigel et al., 1998). Ultimately this affects the accuracy of genetic evaluations (traditional and genomic) and also the prediction of response to selection. In particular, prediction of response to selection can be more sensitive to genetic parameters, especially when correlations switch from positive to negative, as observed 
between milk yield and survival in the current study. These results, which are in agreement with Tsuruta et al. (2004a), show that genetic parameters estimates need to be update regularly. Also, estimating genetic correlations between type and fitness traits over time can also help to identify traits that uniformly predict fitness traits.

Changes in genetic correlations for a trait over time that were observed in our study also have implications for genomic evaluation and GWAS. For traits such as overall type and mammary system, where genetic correlations $(\sim 0.3)$ between distant periods were weak, the reliability of DGV (Haile-Mariam et al., 2015) were lower (0.10) than for pin set (DGV reliability of 0.20), where less change in genetic correlation (i.e., 0.92 to 1 ) was observed. The main reason for the low reliability of overall type and mammary system may be associated with the change in trait definitions introduced in 2007, which unfortunately coincided with the subdivision of bulls into reference (i.e., all daughters of bulls in the reference set were scored before 2007) and validation sets (i.e., all daughters of bulls in the validation set were scored in 2007 and after). This result emphasizes the importance of understanding when genetic correlations between the same trait change, as they have an influence on the accuracy that can be achieved in genomic selection.
The genetic correlation of fat yield with milk decreased from about 0.6 to 0.35 over time, which is in agreement with Tsuruta et al. (2004a), who analyzed Holstein cattle data from the United States. The decline in the genetic correlation of fat yield with milk is associated with the decrease in the genetic correlation of fat-to-protein ratio with milk yield over time $(-0.36$ to -0.47 ) due to strong selection for protein yield that results in a negative genetic trend in fat percent and positive trend in protein percent (M. Haile-Mariam, unpublished results). Despite the negative weight on milk volume in the Australian economic index (Pryce et al., 2009), the genetic trends for milk, protein yield and protein percent were positive because the most likely means to increase protein yield through selection is by increasing total milk yield (Chamberlain et al., 2008; Macciotta et al., 2015). However, fat yield can be changed to some extent independently of milk (Macciotta et al., 2015), for example, due to the outcomes of selection for major genes such as diacylglycerol O-acyltransferase 1 and stearoyl-CoA desaturase (Buitenhuis et al., 2014).

Genetic correlations of the same traits across yeargroups (Table 5) are estimated with high standard errors because such estimates rely on links through numerator relationship matrix of bulls born in different year-groups and through second-crop daughters of

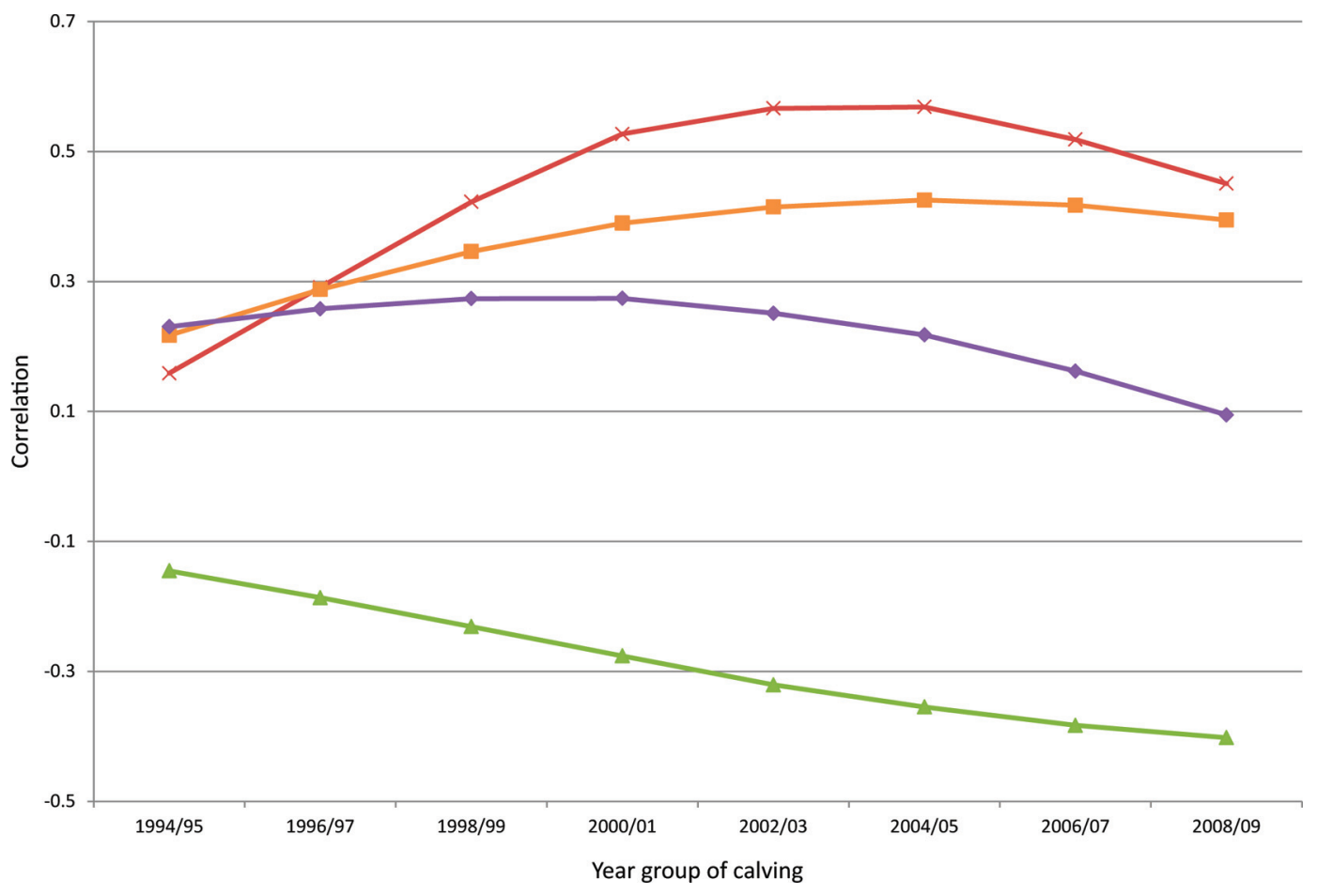

Figure 12. Genetic correlations over time of calving interval with angularity $(\times)$, body depth $(\boldsymbol{\square})$, udder depth $(\mathbf{\Lambda})$, and overall type $(\bullet)$. Color version available online. 
proven bulls. Only a few bulls are used for more than 2 to $3 \mathrm{yr}$, so genetic links are rather limited, especially for type traits, where it is common practice for AI organizations to gather type data on only first-crop daughter groups. In contrast, genetic correlations between pairs of traits over time are estimated with reasonably low standard errors, as shown in Table 6 . In both cases the results in Tables 4, 5, and 6 from the MT analyses are likely to be associated with high sampling error compared with results from the $\mathrm{RR}$ model because the MT models used only a subset of the data. Several additional analyses, which included more time periods as different traits, were attempted but were abandoned due to convergence problems. It is also worth noting that the results that treated traits recorded in different year-groups as different traits and those from the RR models are similar for most traits or trait combinations, with the exceptions of those involving functional traits (i.e., lowly heritable traits).

In our study, changes in genetic variances and correlations over time within a trait or between traits were estimated using a RR model fitting Legendre polynomial of first order (intercept and linear). Higher order of fit, such as quadratic and cubic RR models, resulted in unrealistic estimates where the genetic correlation over time even for traits that did not show marked change became close to zero or negative at the end of the period relative to the beginning (border effects). We assumed that these were artifacts of the model (e.g., Tsuruta et al., 2004b). For the same reason, yeargroup of calving or classification instead of individual years were fitted to model time. This coupled with joint analyses of 2 traits together where 1 trait serves as the control for the other to detect changes in correlation estimates over time was expected to produce sensible results. This is important because changes in correlations within a trait over time could appear to occur even without a major change in trait definition due to selection and linkage disequilibrium (Tsuruta et al., 2004a). Conversely, changes in trait definition that were introduced by Holstein Australia and that involved most type traits in 2007 do not appear to be dramatic when data over a short period of time were considered. For example, the genetic correlation between cows classified in 2006 (as trait 1) and in 2007 (as trait 2) was $0.88 \pm 0.08$ for overall type, which is not significantly different from 1.0. The genetic correlation between cows classified before 2007 (i.e., 1993 to 2006, as trait 1) and in 2007 to 2012 (as trait 2) for the same trait was low at $0.72 \pm 0.06$. This suggests that the change in the trait definition actually happened gradually. Thus, the use of RR models to analyze traits where the change in trait definition is purported to have happened seems acceptable. When analyzing type data of cows scored before or after change in trait definitions, genetic correlation of 0.91 to 0.99 were reported for several traits based on Holstein data in the Netherlands (De Jong and Harbers, 2002).

The primary aim of our study was to investigate genetic changes observed in Australian Holstein cattle over 20 yr. However, based on both RR and MT models, a more pronounced increase was observed in residual variance in traits, such as CI, that could be associated with changes in production system from largely pasture-based seasonal calving system in the 1990s to a mix of year-round and seasonal calving systems in recent years (e.g., Dairy Australia, 2012). The reason for a larger increase in residual variance of protein yield compared with other milk yield traits is not obvious, but may be associated with the wide-spread use of variety of feeding strategies to maximize protein yield. The attempt to use different feeding strategies to maximize protein yield in addition to selection may have been partly prompted by the importance given to protein yield in Australia (Bowman et al., 1996) compared with other yield traits, and this may also have contributed to the increased residual variance over time. Tsuruta et al. (2004a) also observed a larger increase in the residual variance of milk yield and fat yield over time compared with protein yield, which may suggest that the change in residual variance among milk yield traits could vary. Overall, the decline in $\mathrm{h}^{2}$ over time observed in the current study is due to an increase in residual variance due to change in production environment, modification of trait definition, selection, and so on. The observation that the $\mathrm{h}^{2}$ estimates declined over time for overall type and mammary system is in agreement with those observed by Tsuruta et al. (2004b) for final score in US Holstein. Some of the explanations they provided, including selection and reduced genetic diversity as well as redefinition of traits, could also be the reason for the reduction in $\mathrm{h}^{2}$ observed in the current study. For example, the new definition of mammary system and overall type introduced in 2007 includes characteristics of defects, which may have low $\mathrm{h}^{2}$ and contribute to low overall $\mathrm{h}^{2}$ of these traits. The decrease in genetic correlation for overall type over time observed in our study is in agreement with Battagin et al. (2013), who observed the cluster that Australian data belonged to, changed over time (2001 to 2010) more frequently.

The genetic correlations of type traits with survival may be a result of involuntary (e.g., pin set, udder depth) and voluntary (e.g., over all type, mammary system) culling. Part of the reason for voluntary culling on some type traits may be due to the correlation of the type traits with milk yield traits. To assess these, 
the genetic correlations of survival with type traits (angularity, udder depth, overall type, pin set, and body depth) after adjusting for milk yield were re-estimated (Figure 11). In the case of all type traits, except udder depth and pin set, the correlation in absolute values showed some reduction over time, showing that the effect of milk yield on survival was reduced. However, the genetic correlation still remained reasonably high, suggesting that milk yield is not the only cause for the unfavorable correlation between the type traits, such as angularity and body depth, and survival (Figure 11). In the case of udder depth its genetic correlation with survival was higher at the beginning of the study period because the effect of milk yield on culling decisions was removed. In the case of pin set, where milk yield did not have any association, its genetic correlation with survival remained about the same.

\section{CONCLUSIONS}

Analyses of about $20 \mathrm{yr}$ of data on milk yield and functional and type traits of Australian Holstein cows detected some changes in genetic correlations over time within and between traits. The traits that changed most were mammary system, overall type, and angularity, followed by protein and fat yield. This is most likely due to changes in the definitions of these traits in addition to some level of selection. Over the study period, the importance of traits such as milk yield and overall type as criteria for culling was reduced. The genetic correlations of survival with milk, fat, and protein yield declined from $\sim 0.4$ to 0.5 at the beginning of the study period to zero or negative at the end of the study. These changes in genetic correlations over time have implications for the accuracy of prediction equations used for traits such as survival and CI from other traits and, consequently, on the accuracy of genetic evaluation (traditional and genomic) and prediction of response to selection.

\section{ACKNOWLEDGMENTS}

The data used for this study were provided by the Australian Dairy Herd Improvement Scheme database (ADHIS, Melbourne, Australia). The authors wish to thank Holstein Australia (Melbourne, Australia) for the type data. Dairy Futures Cooperative Research Centre (Melbourne, Australia) and ADHIS are acknowledged for financial support.

\section{REFERENCES}

ADHIS (Australian Dairy Herd Improvement Scheme). 2004. ABV Handbook Cows N Genes Workshop Manual. ADHIS, Melbourne, Australia.

Battagin, M., F. Forabosco, J. H. Jakobsen, M. Penasa, T. J. Lawlor, and M. Cassandro. 2012. International genetic evaluation of Holstein bulls for overall type traits and body condition score. J. Dairy Sci. 95:4721-4731.

Battagin, M., F. Forabosco, M. Penasa, and M. Cassandro. 2013. Cluster analysis on across-country genetic correlations for overall type traits and body condition score of Holstein bulls. Livest. Sci. 151:108-114.

Boldman, K. G., A. E. Freeman, B. L. Harris, and A. L. Kuck. 1992. Prediction of sire transmitting abilities for herd life from transmitting abilities for linear type traits. J. Dairy Sci. 75:552-563.

Bowman, P. J., P. M. Visscher, and M. E. Goddard. 1996. Customized selection indices for dairy bulls in Australia. Anim. Sci. 62:393403

Buitenhuis, B., L. L. G. Janss, N. A. Poulsen, L. B. Larsen, M. K. Larsen, and P. Sørensen. 2014. Genome-wide association and biological pathway analysis for milk-fat composition in Danish Holstein and Danish Jersey cattle. BMC Genomics 15:1112.

Chamberlain, A. J., H. C. McPartlan, and M. E. Goddard. 2008. Genes influencing milk production traits predominantly affect one of four biological pathways. Genet. Sel. Evol. 40:79-89.

Dairy Australia. 2012. Australian Dairy Industry In Focus 2012. Accessed July 2015. http://www.dairyaustralia.com.au/ / media/Documents/Stats\%20and\%20markets/In\%20Focus/ Australian\%20Dairy\%20Industry\%20In\%20Focus\%202012.pdf.

De Jong, G., and A. G. F. Harbers. 2002. Determining changes in definition of conformation traits and the effect on International evaluations. Interbull Bull. 29:39-42.

Gilmour, A. R., B. J. Gogel, B. R. Cullis, and R. Thompson. 2009. ASReml User Guide Release 3.0. VSN International Ltd., Hemel Hempstead, UK.

Haile-Mariam, M., O. Gonzalez-Recio, and J. E. Pryce. 2014. Prediction of liveweight of cows from type traits and its relationship with production and fitness traits. J. Dairy Sci. 97:3173-3189.

Haile-Mariam, M., J. E. Pryce, C. Schrooten, and B. J. Hayes. 2015. Including overseas performance information in genomic evaluations of Australian dairy cattle. J. Dairy Sci. 98:3443-3459.

Jamrozik, J., and L. R. Schaeffer. 1991. Procedures for updating solutions to animal models as data accumulate. J. Dairy Sci. 74:19932000 .

Macciotta, N. P. P., C. Dimauro, D. J. Null, G. Gaspa, M. Cellesi, and J. B. Cole. 2015. Dissection of genomic correlation matrices of US Holsteins using multivariate factor analysis. J. Anim. Breed. Genet. 132:9-20.

Pryce, J. E., J. H. J. van der Werf, M. Haile-Mariam, B. Malcolm, and M. E. Goddard. 2009. Updated index weights for the Australian Profit Ranking in dairy cattle. Pages 143-146 in Proc. Assoc. Advmt. Anim. Breed. Genet. Vol. 18.

Tsuruta, S., I. Misztal, and T. J. Lawlor. 2004a. Genetic correlations among production, body size, udder, and productive life traits over time in Holsteins. J. Dairy Sci. 87:1457-1468.

Tsuruta, S., I. Misztal, T. J. Lawlor, and L. Klei. 2004b. Modeling final scores in US Holsteins as a function of year of classification using a random regression model. Livest. Prod. Sci. 91:199-207.

Visscher, P. M., and M. E. Goddard. 1995. Genetic parameters for milk yield, survival, workability, and type traits for Australian dairy cattle. J. Dairy Sci. 78:205-220.

Weigel, K. A., T. J. Lawlor, P. M. VanRaden, and G. R. Wiggans 1998. Use of linear type and production data to supplement early predicted transmitting abilities for productive life. J. Dairy Sci. 81:2040-2044. 